\title{
Effect of Operating Conditions on the Ceramic Particles Drying Process by Superheated Steam in the Packed Bed Dryer
}

\author{
Thi Thu Hang Tran ${ }^{1}$, Kieu Hiep Le ${ }^{1^{*}}$, Thi Thu Huong Tran ${ }^{2}$ \\ ${ }^{1}$ Hanoi University of Science and Technology, No.1 Dai Co Viet str., Hai Ba Trung dist., Hanoi, Viet Nam \\ ${ }^{2}$ University of Economics - Technology for Industries, 456 Minh Khai str., Hai Ba Trung dist., Hanoi, Viet Nam \\ Received: April 05, 2020; Accepted: November 12, 2020
}

\begin{abstract}
A novel model of ceramic particle drying by superheated steam in the packed bed dryer is applied to examine the effects of operating conditions on the drying process. It is shown that the drying kinetic has two drying stages: the evaporation flux firstly increases to the maximum value while particle temperature is remained as saturation temperature, then the evaporation flux decreases to the zero, and particle temperature rises to the equilibrium temperature. Results also illustrate that the drying process is faster at the thinner bed layer, smaller particle diameter, and higher initial vapor velocity and temperature.
\end{abstract}

Keywords: Superheated steam drying, ceramic drying, packed bed

\section{Introduction}

Super-heated steam drying (SSD) has been applied in many industrial fields such as chemical engineering, food engineering, coal, etc. because it is cheaper and more friendly than the hot air drying (HAD) technique [1]. In SSD, super-heated steam is used as a drying agent so the exhausted agent can be reused or recycled. Thus, SSD gives higher energy efficiency and lower carbon dioxide emission. At temperature above the inversion temperature, the drying rate in SSD is higher than that in HAD. Additionally, due to no oxygen, the quality of product dried in SSD is better than that in HAD $[2,3]$. In terms of dryer system, a packed bed dryer is one of the common techniques because it is a simple operation and low mechanical damage to the material [4].

The study of individual particle drying kinetic has been concerned as a solution to complex transports occurring inside the packed bed. There have been several models that can be categorized into empirical models and theoretical models. The empirical models are easy to implement in the macroscale model $[5,6]$. However, these were obtained from several sets of the experiment so the application ability is limited in the experiment condition. Regarding theoretical models, the partial distributions of temperature and moisture content in the particle often are considered [7-9]. In these theoretical models, moisture content gradient is driving force of

*Corresponding author: Tel.: (+84) 971381294

Email: hiep.lekieu@hust.edu.vn only water or both liquid water and water vapor transport inside particle. In the previous own work [10], a novel model was applied and validated for the multiscale model of ceramic particles drying in the packed bed dryer by super-heated steam. In this work, Reaction Engineering Approach (REA) applied for drying is analogy with chemical reaction kinetics. This model has the advantage that the model parameters are determined from one set of experimental data, but it was successful validated for other conditions. After that, the macro-scale model of super-heated steam packed bed drying is built by volume averaging technique.

In this work, the built model is simulated for a range of operating conditions to examines the effects of drying conditions on the drying process of ceramic particles in a packed bed dryer. From this, advice will be given to increase the energy efficiency of the system.

\section{Mathematical model}

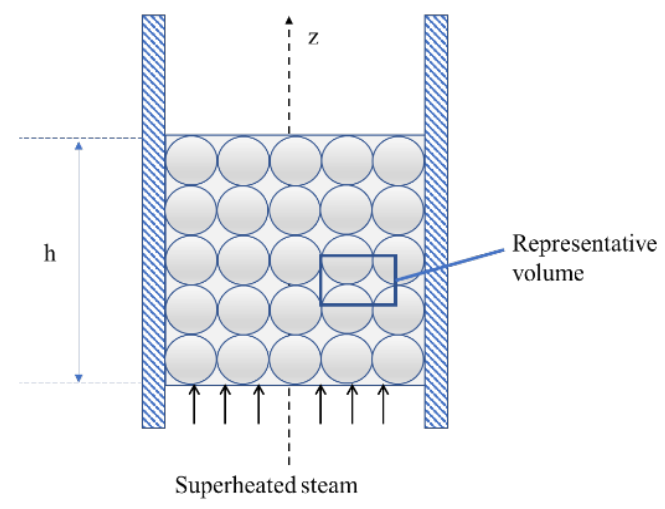

Fig. 1. Geometry of packed bed 
The packed bed dryer is composed of uniform spherical ceramic particles and a super-heated steam phase as Fig.1. It is assumed that the particle porosity is uniform, and flow is plug flow, viscous dissipation and compression are negligible, vapor evaporated from particles is much smaller than the inlet steam flow, the bed is isotropic and homogeneous porous media.

The mathematical model is developed and verified in Ref. [10] in detail. In this paper, the model is only recalled briefly in following sections.

\subsection{Heat and mass transfer}

Heat and mass conservation equations were developed based on volume averaging technique $[9,11]$. For the fluid phase, the temperature change is the result of enthalpy flow from the vapor phase, heat flow from evaporated vapor, convective heat transfer from drying particles as Eq. 1 :

$$
\begin{aligned}
& \psi c_{p, v} \rho_{v} \frac{\partial T_{v}}{\partial t}+c_{p, v} \rho_{v} v_{v} \frac{\partial T_{v}}{\partial z}=\frac{\partial}{\partial z}\left(\lambda_{v, e f f} \frac{\partial T_{v}}{\partial z}\right) \\
& -\dot{m}_{v} A_{v} c_{p, v}\left(T_{v}-T_{s}\right)-\alpha A_{v}\left(T_{v}-T_{s}\right)
\end{aligned}
$$

where, $\psi$ is bed porosity; $c_{p, v}[\mathrm{~J} / \mathrm{kgK}], \rho_{v}\left[\mathrm{~kg} / \mathrm{m}^{3}\right], v_{v}$ $[\mathrm{m} / \mathrm{s}], \lambda_{v, \text { eff }}[\mathrm{W} / \mathrm{mK}]$ are heat capacity, density, velocity, effective heat conductivity of vapor, respectively; $T_{v}$ and $T_{s}[\mathrm{~K}]$ are vapor temperature and solid temperature, respectively. $A_{v}\left[\mathrm{~m}^{2} / \mathrm{m}^{3}\right]$ is specific area. $\alpha\left[\mathrm{W} / \mathrm{m}^{2} \mathrm{~K}\right]$ is the heat transfer coefficient. The evaporation flux $\dot{m}_{v}\left[\mathrm{~kg} / \mathrm{m}^{2} \mathrm{~s}\right]$ is calculated as in Section 2.3.

The enthalpy flow change and mass conservation of solid phase are expressed as:

$$
\begin{aligned}
& (1-\psi)\left\langle c_{p, s, e f f} \rho_{s, e f f}\right\rangle \frac{\partial T_{s}}{\partial t}=\frac{\partial}{\partial z}\left(\lambda_{s, e f f} \frac{\partial T_{s}}{\partial z}\right) \\
& -\dot{m}_{v} A_{v} \Delta h_{e v p}+\alpha A_{v}\left(T_{v}-T_{s}\right) \\
& (1-\psi) \frac{\partial \rho_{s, e f f}}{\partial t}=-\dot{m}_{v} A_{v}
\end{aligned}
$$

in which $c_{p, s, e f f}[\mathrm{~J} / \mathrm{kgK}], \rho_{s, \text { eff }}\left[\mathrm{kg} / \mathrm{m}^{3}\right], \lambda_{s, \text { eff }}[\mathrm{W} / \mathrm{mK}]$ and $T_{s}[\mathrm{~K}]$ are effective heat capacity, effective density, and effective heat conductivity, temperature of solid phase, respectively. $\Delta h_{\text {evp }}[\mathrm{J} / \mathrm{kg}]$ is the evaporation latent heat. These effective physical properties in the above equations of the packed bed are calculated from:

$$
\begin{aligned}
& \rho_{s, e f f}=\rho_{s}(1+X) \\
& \left\langle c_{p, s, e f f} \rho_{s, e f f}\right\rangle=\rho_{s}\left(c_{p, s}+X c_{p, l}\right)
\end{aligned}
$$

$$
\begin{aligned}
& \lambda_{s, e f f}=(1-\psi)\left(\lambda_{s} \frac{m_{s}}{V}+\lambda_{l} \frac{m_{l}}{V}\right)= \\
& (1-\psi)\left(\lambda_{s} \rho_{s}+\lambda_{l} \rho_{l} X\right) \\
& \lambda_{f, e f f}=\psi \lambda_{v}
\end{aligned}
$$

in which, $X$ is moisture content $(\mathrm{kg}$ water / $\mathrm{kg}$ dry basis) of the bed.

\subsection{Thermal boundary conditions}

The temperature of vapor is assumed as constant at the packed bed inlet:

$$
\frac{\partial T_{v}}{\partial t}=0
$$

Particle temperature at inlet is calculated by:

$$
\begin{aligned}
& (1-\psi)\left\langle c_{p, s, e f f} \rho_{s, \text { eff }}\right\rangle \frac{\partial T_{s}}{\partial t}=\left.\frac{\partial}{\partial z}\left(\lambda_{s, \text { eff }} \frac{\partial T_{s}}{\partial z}\right)\right|_{z=0} \\
& -\dot{m}_{v} A_{v} \Delta h_{\text {evp }}+\alpha A_{v}\left(T_{v}-T_{s}\right)
\end{aligned}
$$

At the outlet, energy conservation for particles and vapor is calculated as:

$$
\begin{aligned}
& (1-\psi)\left\langle c_{p, s, e f f} \rho_{s, e f f}\right\rangle \frac{\partial T_{s}}{\partial t}=\left.\frac{\partial}{\partial z}\left(\lambda_{s, e f f} \frac{\partial T_{s}}{\partial z}\right)\right|_{z=h} \\
& -\dot{m}_{v} A_{v} \Delta h_{\text {evp }}+\alpha A_{v}\left(T_{v}-T_{s}\right)
\end{aligned}
$$

In the above equations, evaporation flux $\dot{m}_{v}$ is determined by Reaction Engineering Approach developed for super-heated steam drying.

\subsection{Drying kinetic}

Drying dynamic is the difference of vapor density at the particle surface and bulk vapor $\rho_{v, \text { surf }}, \rho_{v, b}\left(\mathrm{~kg}\right.$ vapor $\left./ \mathrm{m}^{3}\right)$ as

$$
\dot{m}_{v}=-\beta\left(\rho_{v, \text { surf }}-\rho_{v, b}\right)
$$

where $\beta(\mathrm{m} / \mathrm{s})$ is the mass transfer coefficient. The relationship between vapor density at the particle surface and at the pure water droplet surface is:

$$
\rho_{v, \text { surf }}=\exp \left(\frac{-\Delta E_{v}}{R T_{s}}\right) \rho_{v, \text { sat }}\left(T_{s}\right)
$$

where the activation energy $\Delta E_{v}$ of the particle and the equilibrium activation energy $\Delta E_{v, e q}$ is determined by experimental data [10]:

$$
\frac{\Delta E_{v}}{\Delta E_{v, e q}}=\frac{7.42 \times 10^{-3}}{\left(X-X_{e q}\right)+7.63 \times 10^{-3}}
$$




$$
\Delta E_{v, e q}=R T_{v, b} \ln \left(\frac{p_{v, b}}{p_{v, s a t}\left(T_{v, b}\right)}\right)
$$

Heat and mass transfer coefficients between particle and vapor are calculated as

$$
\begin{aligned}
& N u=2+0.616 \operatorname{Re}^{0.52} \operatorname{Pr}^{\frac{1}{3}} \\
& S h=0.144+0.579 R e^{0.5} S c^{1 / 3}
\end{aligned}
$$

\section{Results and discussion}

As mentioned, the mathematical model was successful validated by a comparison between predictive and experimental data in terms of drying rate and outlet vapor temperature as Fig.2 and Fig.3 as shown in [11].

Here, the model is applied to examine the effect of particle diameter $d[\mathrm{~m}]$, bed height $h[\mathrm{~m}]$, inlet vapor temperature $T_{v, \text { in }}\left[{ }^{\circ} \mathrm{C}\right]$, and inlet vapor velocity $v_{\text {in }}[\mathrm{m} / \mathrm{s}]$ on the ceramic particle drying. In each analysis, there is only one variable, other variables are kept constant.

\subsection{Effect of particle diameter}

Evolutions of evaporation flux, vapor temperature, and solid temperature at the packed bed outlet over time are presented in Fig.4-6 corresponding with different particle diameters. It is observed in Fig.4 that, $m_{v}$ increases when particle diameter reduces resulting in the shorter drying time. The reason is that the faster heat and mass transfers ocurrs in drying process of smaller particles. In these cases, the evaporation flux increases to the maximum value then it decreases gradually. This trend is different from the drying kinetic of single particle which experiences the constant drying period followed by falling drying period. The increase of drying flux in the first period can be explained by the change of vapor temperature flowing through the bed as Fig.6. The particle water content reduces which gives the decrease of vapor density on the particle surface, but the heat and mass transfer coefficient rise due to the accession of thermal conductivity and reduction of viscosity of vapor at higher vapor temperature. This first drying period corresponds with the constant solid temperature stage (Fig.5). However, after a certain period, the heat and mass transfer from vapor are not enough to remain the high evaporation speed and constant solid temperature, the evaporation flux goes to the falling period. In this, evaporation flux drops to zero at the end of the drying process while the solid temperature increases to the equilibrium temperature (Fig.5). This is because of the increase in the evaporation energy barrier corresponding with the reduction of particle moisture content.

It can be observed in Fig.5 that the vapor temperature at bigger particle is higher than that at smaller particle due to the slower drying speed of big particle. However, the vapor at big particle drying bed changes slower to the equilibrium temperature (for $d=0.015 \mathrm{~m}$, vapor temperature reaches the $m_{v}$ equilibrium temperature after $800 \mathrm{~s}$ while for $d=0.005 \mathrm{~m}$, this period is about $400 \mathrm{~s}$ ). The low heat and mass transfer coefficients are also the reason of this comparison.

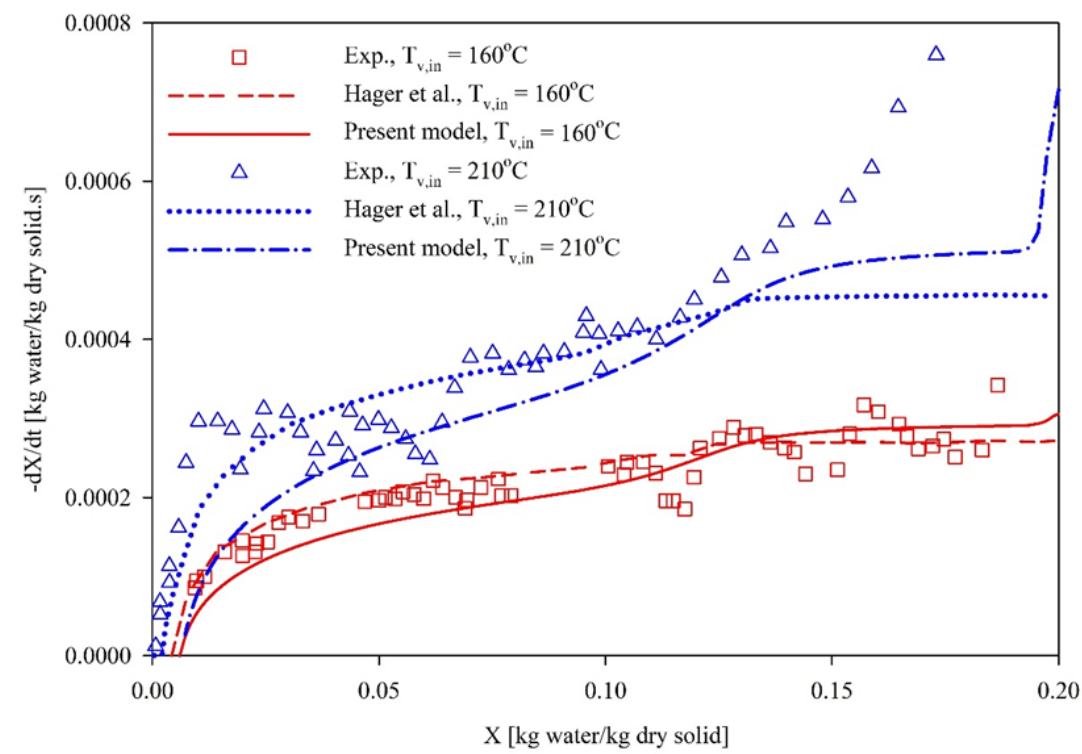

Fig. 2. Comparisons of drying rates obtained from simulations and measurements. 


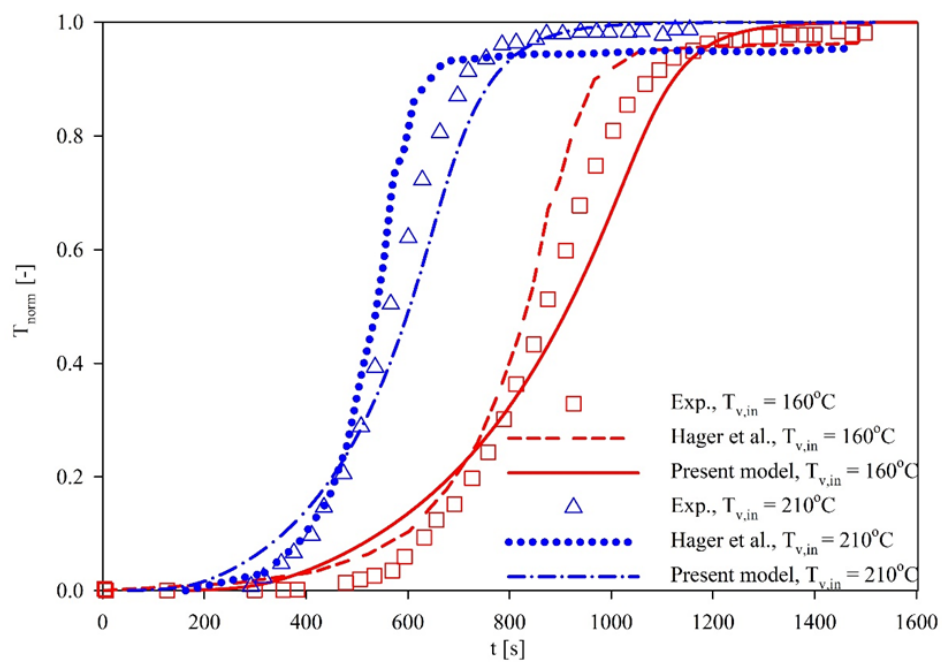

Fig. 3. Comparisons of outlet vapor temperature obtained from experiments and simulations.

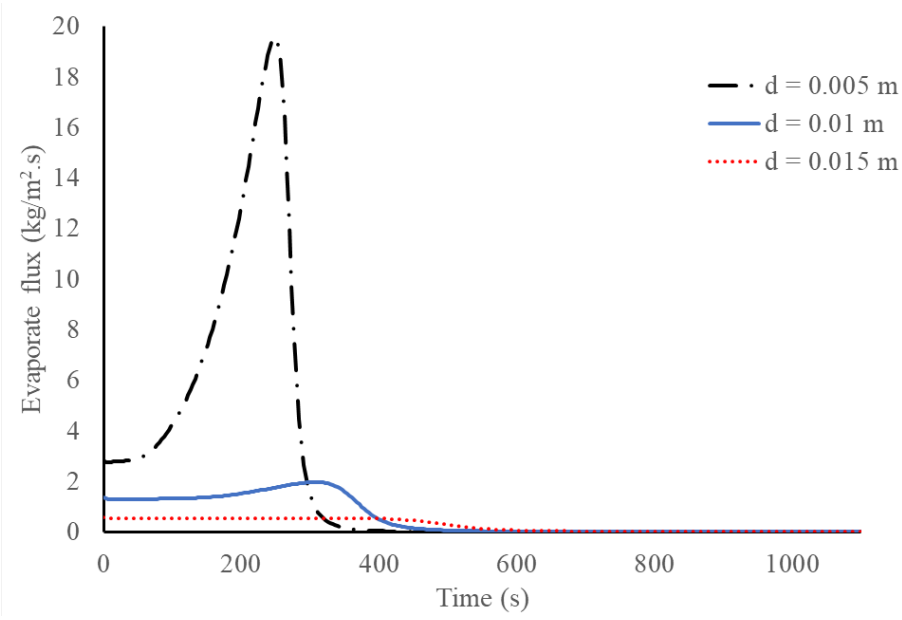

Fig. 4. Evaporation flux at the middle of the bed at $T_{v, \text { in }}=210{ }^{\circ} \mathrm{C}, v_{i n}=1.5 \mathrm{~m} / \mathrm{s}, X_{w, i n}=0.2 \mathrm{~kg} / \mathrm{kg}, h=0.1 \mathrm{~m}$

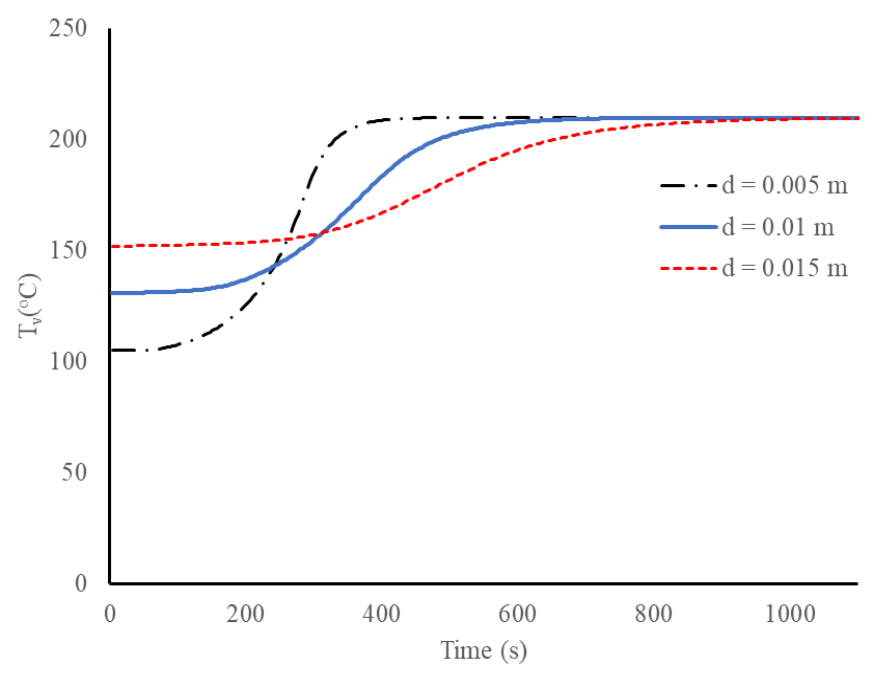

Fig. 5. Vapor temperature, $T_{v}$ at the middle of the bed at $T_{v, \text { in }}=210^{\circ} \mathrm{C}, v_{\text {in }}=1.5 \mathrm{~m} / \mathrm{s}, X_{w, i n}=0.2 \mathrm{~kg} / \mathrm{kg}, h=0.1 \mathrm{~m}$ 


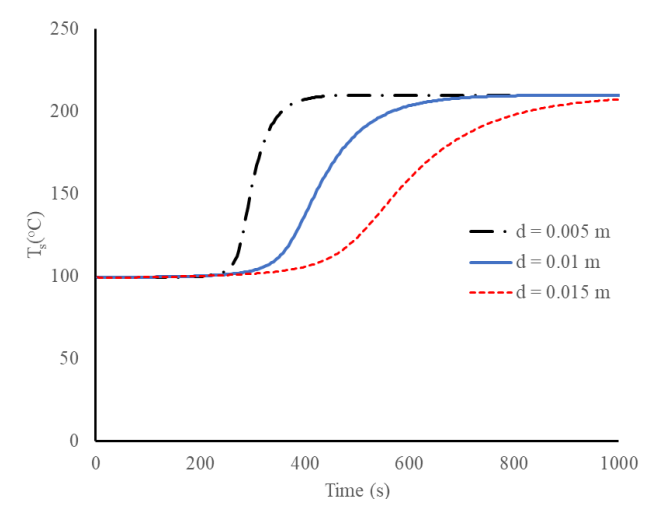

Fig. 6. Particle temperature, $T_{s}$ at the middle of the bed at $T_{v, \text { in }}=210{ }^{\circ} \mathrm{C}, v_{\text {in }}=1.5 \mathrm{~m} / \mathrm{s}, X_{w, \text { in }}=0.2 \mathrm{~kg} / \mathrm{kg}$, $h=0.1 \mathrm{~m}$

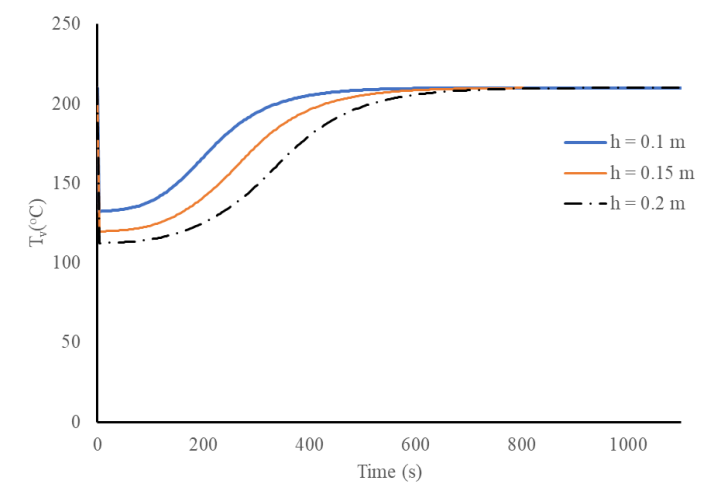

Fig. 8. Vapor temperature, $T_{v}$ at the middle of the bed at $T_{v, \text { in }}=210{ }^{\circ} \mathrm{C}, v_{i n}=1.5 \mathrm{~m} / \mathrm{s}, X_{w, \text { in }}=0.2 \mathrm{~kg} / \mathrm{kg}$, $d=0.01 \mathrm{~m}$

Regarding Fig.6, during the first drying period, particle temperature remains constant because the heat flow is enough for only evaporation. After the maximum point of evaporation flux, the solid particle starts to increase gradually to the vapor temperature at the end. Besides, smaller particle temperature reaches the maximum temperature earlier than the bigger particle; like the vapor temperature change, the faster heat transfer of smaller particles is the reason for this observation.

\subsection{Effect of bed height}

Comparisons of drying of middle bed at different bed heights are presented in Fig.7-9. It can be seen in Fig.7 that the thinner particle layer gives faster drying and shorter drying time. The reason is that at the thin particle layer, the vapor flows through the shorter distance so the vapor enthalpy used for heat and mass transfer is lower resulting in the higher vapor temperature (Fig.8).

In case of thin bed particle temperature remains constant corresponding with the increase of evaporation flux for a shorter time. The particle

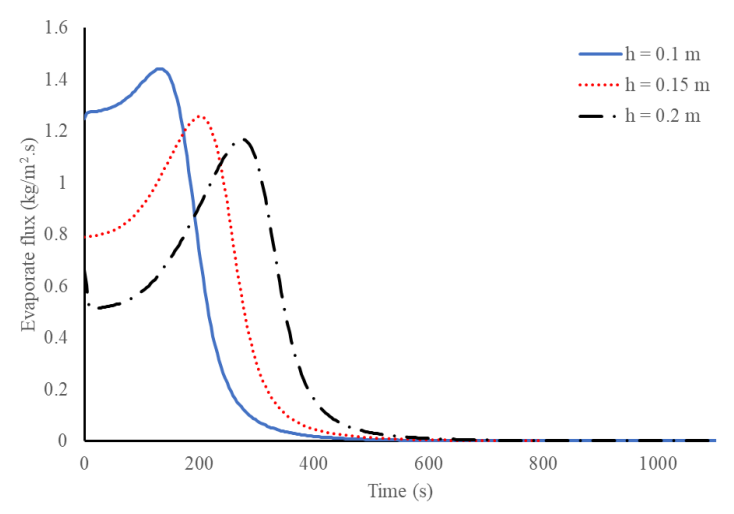

Fig. 7. Evaporation flux, $m_{v}$ at the middle of the bed at $T_{v, \text { in }}=210{ }^{\circ} \mathrm{C}, v_{\text {in }}=1.5 \mathrm{~m} / \mathrm{s}, X_{w, \text { in }}=0.2 \mathrm{~kg} / \mathrm{kg}$, $d=0.01 \mathrm{~m}$

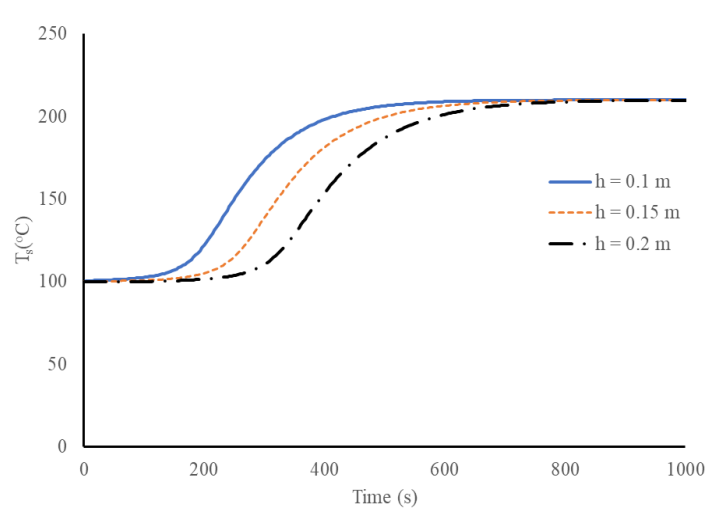

Fig. 9. Particle temperature, $T_{s}$ at the middle of the bed at $T_{v, \text { in }}=210^{\circ} \mathrm{C}, v_{\text {in }}=1.5 \mathrm{~m} / \mathrm{s}, X_{w, \text { in }}=0.2 \mathrm{~kg} / \mathrm{kg}$, $d=0.01 \mathrm{~m}$

temperature and vapor temperature reach the equilibrium temperature slower at the thicker particle layer. Thus, to obtain faster drying, a thinner particle layer is necessary.

\subsection{Effect of vapor temperature}

Changes of evaporation flux, vapor temperature, and particle temperature versus time under different inlet vapor temperatures are shown in Fig.10-12. It is observed that the drying occurs faster at higher inlet vapor temperature. Hence, particles drying at lower inlet vapor temperature need longer time to reach the equilibrium moisture content. The maximum evaporate flux at $T_{v, \text { in }}=240{ }^{\circ} \mathrm{C}$ is $1.78 \mathrm{~kg} / \mathrm{m}^{2} \mathrm{~s}$ while at $T_{v, \text { in }}=180{ }^{\circ} \mathrm{C}$, it is $1.18 \mathrm{~kg} / \mathrm{m}^{2}$.s. Vapor temperature (see Fig.11) drops to minimum temperature then increases gradually for every case, but at low inlet vapor temperature, the vapor temperature changes slower due to the slow heat and mass transfers (curve slope is small). Fig.12 shows the faster particle temperature change at higher inlet vapor temperature. Particularly, at $T_{v, \text { in }}=240{ }^{\circ} \mathrm{C}$, the constant particle temperature as saturated temperature is remained for 
$100 \mathrm{~s}$ while at $T_{v, \text { in }}=180^{\circ} \mathrm{C}$ it is remained for $160 \mathrm{~s}$. However, in all cases, heat transfer phenomena cease at almost the same time due to the differences between initial vapor temperature and particle temperature and the equilibrium values increase corresponding with the increase of inlet vapor temperature.

\subsection{Effect of inlet vapor velocity}

Evolutions of evaporation flux, vapor temperature and particle temperature at the middle

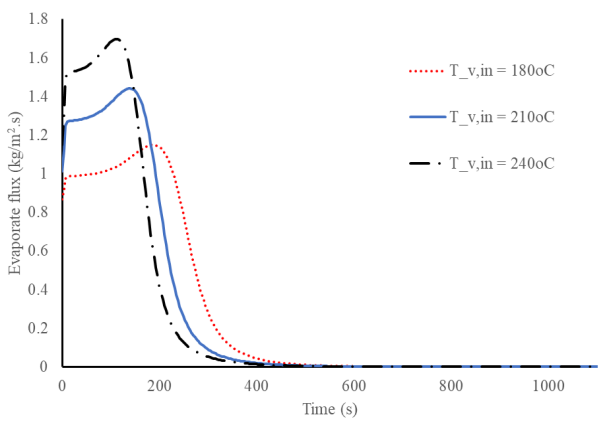

Fig. 10. Evaporation flux, $m_{v}$ at the middle of the bed at $h=0.1 \mathrm{~m}, v_{\text {in }}=1.5 \mathrm{~m} / \mathrm{s}, X_{w, \text { in }}=0.2 \mathrm{~kg} / \mathrm{kg}$, $d=0.01 \mathrm{~m}$

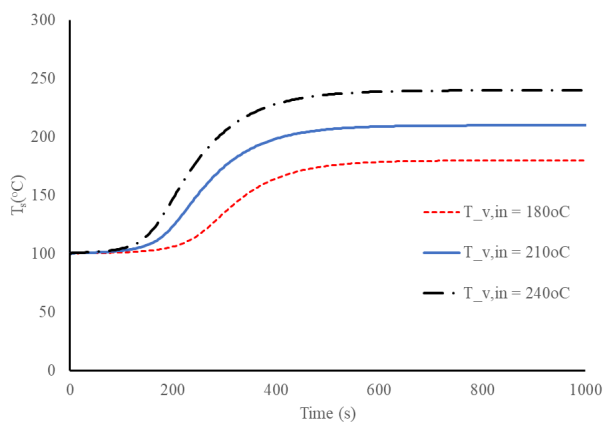

Fig. 12. Particle temperature, $T_{s}$ at the middle of the bed at $h=0.1 \mathrm{~m}, v_{\text {in }}=1.5 \mathrm{~m} / \mathrm{s}, X_{w, \text { in }}=0.2 \mathrm{~kg} / \mathrm{kg}$, $d=0.01 \mathrm{~m}$

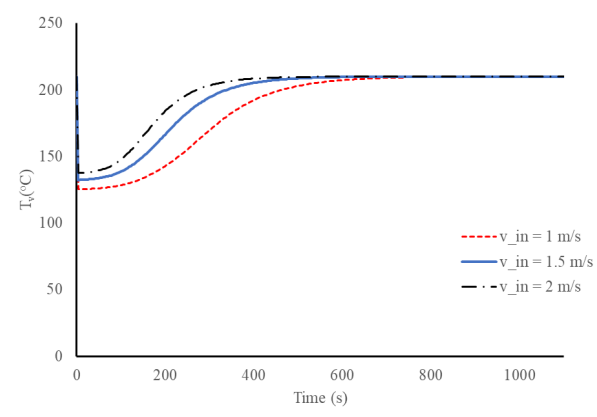

Fig. 14. Vapor temperature, $T_{v}$ at the middle of the bed at $h=0.1 \mathrm{~m}, T_{v, \text { in }}=210^{\circ} \mathrm{C}, X_{w, \text { in }}=0.2 \mathrm{~kg} / \mathrm{kg}$, $d=0.01 \mathrm{~m}$ bed under different inlet vapor velocity are illustrated in Figs. 13-15.

The higher inlet velocity gives the increase in the heat and mass transfer flow rate between particles and vapor resulting in higher evaporation flux and shorter drying time. At $v_{v, \text { in }}=2 \mathrm{~m} / \mathrm{s}$, particle need $353 \mathrm{~s}$ to stop evaporation while at $v_{v, \text { in }}=1 \mathrm{~m} / \mathrm{s}$, this period is 532s. Similarly, vapor temperature takes a longer time to reach the equilibrium temperature when the inlet vapor temperature is lower.

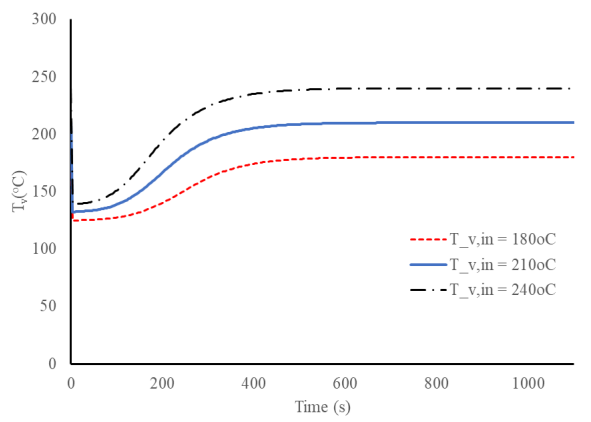

Fig. 11. Vapor temperature, $T_{v}$ at the middle of the bed at $h=0.1 \mathrm{~m}, v_{\text {in }}=1.5 \mathrm{~m} / \mathrm{s}, X_{w, \text { in }}=0.2 \mathrm{~kg} / \mathrm{kg}$, $d=0.01 \mathrm{~m}$

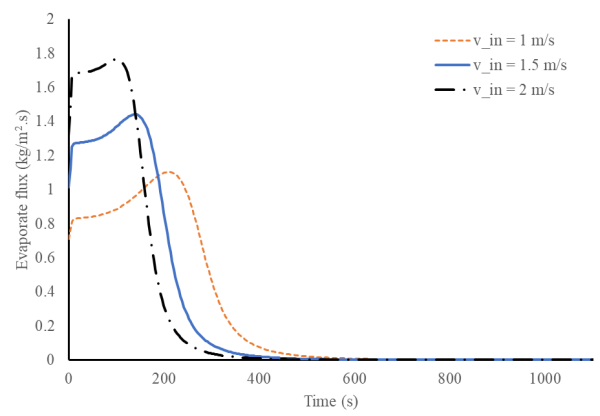

Fig. 13. Evaporation flux, $m_{v}$ at the middle of the bed at $h=0.1 \mathrm{~m}, T_{v, \text { in }}=210 \mathrm{~m} / \mathrm{s}, X_{w, \text { in }}=0.2 \mathrm{~kg} / \mathrm{kg}$, $d=0.01 \mathrm{~m}$

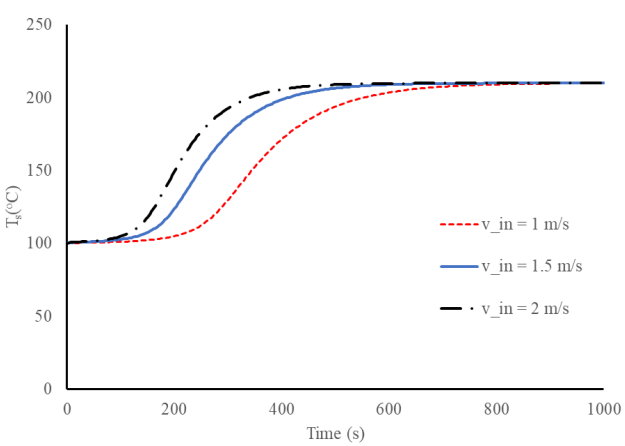

Fig. 15. Particle temperature, $T_{s}$ at the middle of the bed at $h=0.1 \mathrm{~m}, T_{v, \text { in }}=210^{\circ} \mathrm{C}, X_{w, \text { in }}=0.2 \mathrm{~kg} / \mathrm{kg}$, $d=0.01 \mathrm{~m}$ 
In Fig.14, vapor temperature drops suddenly to the minimum temperature then increases gradually to the equilibrium temperature $\left(210^{\circ} \mathrm{C}\right)$. At $v_{v, \text { in }}=1 \mathrm{~m} / \mathrm{s}$, vapor temperature is $210^{\circ} \mathrm{C}$ at $653 \mathrm{~s}$ while this temperature is $210^{\circ} \mathrm{C}$ at $420 \mathrm{~s}$. The first drying period of particle is also longer at lower inlet vapor temperature so the constant particle temperature period at cooler drying is longer than hotter drying. After that, the particle temperature accelerates to the equilibrium temperature when heat transfer between particle and vapor stops at the almost same time with time vapor temperature ceases to change.

\section{Conclusion}

In this work, the impact of operating conditions on the super-heated steam drying by a packed bed of ceramic particles is analyzed based on the own published model. The results show that in order to accelerate evaporation, it is necessary to use the smaller particle, thinner bed layer, higher inlet vapor temperature, and faster inlet vapor velocity. Changes of drying data in the packed bed are different compared with drying kinetic of single particle. Under every condition, particles experience two drying periods: in the first period, evaporation flux increases to the maximum due to the change of vapor temperature resulting in the change of vapor physical properties, particle temperature remains as saturation temperature; in the second period, the evaporation flux reduces and particle temperature increases because of the fast increase in activation energy barrier.

This model can be implemented in the other dryers without any obstacle; however, it has several simplified assumptions, so the application ability is limited for the plug flow. If the partial gradient of vapor flow cannot be negligible, it is necessary to extend the developed model to the $3 \mathrm{D}$ model. In this case, the presented model should be combined with the momentum equation and the other equations which account for the effects of the dryer wall and pressure drop on the drying. In this case, the model computational fluid dynamic tool such as ANSYS Fluent or COMSOL Multiphysics which have many effective tools for complex mathematical models. That is also the next step of authors' project.

\section{Acknowledgments}

This research is funded by Vietnam National Foundation for Science and Technology
Development (NAFOSTED) under grant number 107.99-2018.06.

\section{References}

[1]. Mujumdar, A.S. Handbook of industrial drying; CRC Press: Boca Raton, 2014.

[2]. Romdhana, H.; Bonazzi, C.; Esteban-Decloux, M. Superheated Steam Drying: An Overview of Pilot and Industrial Dryers with a Focus on Energy Efficiency. Drying Technology 2015, 33(10), 1255-1274.

[3]. Zhu, J.; Wang, Q.; Lu, X. Status and Developments of Drying Low Rank Coal with Superheated Steam in China. Drying Technology 2015, 33(9), 1086-1100.

[4]. Prado, M.M.; Mazzini Sartori, D.J. Heat and Mass Transfer in Packed Bed Drying of Shrinking Particles. In Mass transfer in multiphase systems and its applications; El-Amin, M., Ed.; InTech: Rijeka, 2011.

[5]. Adamski, R.; Pakowski, Z. Identification of Effective Diffusivities in Anisotropic Material of Pine Wood during Drying with Superheated Steam. Drying Technology 2013, 31(3), 264-268.

[6]. Pakowski, Z.; Adamski, R.; Kwapisz, S. Effective diffusivity of moisture in low rank coal during superheated steam drying at atmospheric pressure. Chemical and Process Engineering 2012, 33(1), 4351.

[7]. Ezhil, C. Superheated steam drying of foods-A review. World journal of dairy and food sciences 2010, 5(2), 214-217.

[8]. Sehrawat, R.; Nema, P.K.; Kaur, B.P. Effect of superheated steam drying on properties of foodstuffs and kinetic modeling. Innovative Food Science \& Emerging Technologies 2016, 34, 285-301.

[9]. Messai, S.; El Ganaoui, M.; Sghaier, J.; Chrusciel, L.; Slimane, G. Comparison of 1D and 2D models predicting a packed bed drying. International Journal for Simulation and Multidisciplinary Design Optimization 2014, 5(10), A14.

[10]. Le, K.H.; Tran, T.T.H.; Nguyen, N. an; Kharaghani, A. Multiscale modelling of superheated steam drying of particulate materials. Chemical Engineering \& Technology 2020.

[11]. Hager, J.; Wimmerstedt, R.; Whitaker, S. Steam drying a bed of porous spheres: Theory and experiment. Chemical Engineering Science 2000, 55(9), 1675-1698. 